\title{
Preferred and actual methods of hysterectomy: A survey of current practices among members of the South African Society of Obstetricians and Gynaecologists
}

\author{
A Chrysostomou, ${ }^{1} \mathrm{MD}, \mathrm{FCOG}(\mathrm{SA})$, MMed; D Djokovic, ${ }^{2,3} \mathrm{MD}, \mathrm{PhD}$ \\ ${ }^{1}$ Department of Obstetrics and Gynaecology, Faculty of Health Sciences, University of the Witwatersrand, Johannesburg, South Africa \\ ${ }^{2}$ Department of Obstetrics and Gynecology, Nova Medical School, Faculdade de Ciências Médicas, Nova University of Lisbon, Portugal \\ ${ }^{3}$ Department of Obstetrics and Gynecology, Hospital S. Francisco Xavier, Centro Hospitalar de Lisboa Ocidenta, Lisbon, Portugal
}

Corresponding author: A Chrysostomou (andreas.chrysostomou@wits.ac.za)

\begin{abstract}
Background. Hysterectomy remains one of the most common operative procedures for benign uterine diseases. Total abdominal hysterectomy (TAH) constitutes the most common approach despite the advantages of minimally invasive hysterectomy (MIH).

Objectives. To explore the current opinion on hysterectomy choices amongst members of the South African Society of Obstetricians and Gynaecologists (SASOG), as well as the perceptions and potential barriers that may inhibit gynaecologists from offering MIH to their patients. Methodology. An anonymous survey designed to explore the preferences of practising obstetrician gynaecologists regarding the optimal hysterectomy procedure, and perceived barriers towards $\mathrm{MIH}$.

Results. The average age of the respondents $(N=152)$ was 45.7 years, with $88.2 \%$ having $>5$ years' experience in private practice. When asked about the preferred route of hysterectomy for themselves or their relatives, $46.2 \%$ chose vaginal hysterectomy (VH), $25.4 \%$ chose total laparoscopic hysterectomy (TLH), 15\% chose laparoscopic assisted vaginal hysterectomy (LAVH) and $8.5 \%$ chose TAH. However, the most commonly performed hysterectomy procedure undertaken by the respondents in the last year was TAH. Only half of the respondents wished to increase their rate of $\mathrm{VH}$ and a lesser number to extend their laparoscopic hysterectomy rates.

Conclusion. Although the majority of the respondents preferred the minimally-invasive VH or TLH for themselves or their relatives, TAH remains the most common hysterectomy method among SA gynaecologists. This difference could present an ethical dilemma for the gynaecologist. The desire of a minority to change their approach to $\mathrm{VH}$ indicates the difficulty in changing attitudes and the need to promote $\mathrm{VH}$ as a technique within SASOG.
\end{abstract}

S Afr J Obstet Gynaecol 2020;26(1):29-34. https://doi.org/10.7196/SAJOG.2020.v26i1.1558

Hysterectomy is one of the most common operative procedures for benign gynaecological diseases. ${ }^{[1]}$ It can be performed abdominally, vaginally or laparoscopically, with or without robotic assistance. At present, total abdominal hysterectomy (TAH) constitutes the most common approach, despite the fact that vaginal hysterectomy (VH) or laparoscopic hysterectomy (LH) should be the preferred route based on their well-documented benefits. ${ }^{[2]}$

It is estimated that $\sim 20 \%$ of women living in England and Wales will have undergone a hysterectomy before the age of 55 years. Most surgeons perform up to $80 \%$ of these procedures via the abdominal route. ${ }^{[3,4]}$ The reason for this can be explained, in part, by personal preference, but is mainly due to a lack of training and experience, thus resulting in the surgeon's reluctance to perform $\mathrm{VH}$. This is the case particularly in nulliparous woman in the presence of uterine enlargement, in women with previous gynaecological surgery or women who have undergone a previous caesarean section (CS). The above factors should not be considered as contraindications to performing $\mathrm{VH}^{[5-7]}$ In the USA, one in three women undergoes hysterectomy by the age of 60 years. Of these women, $22 \%$ have undergone $\mathrm{VH}$. The introduction of $\mathrm{LH}$ increased the number of $\mathrm{VH}$ (if the uterus is removed by that route) to $33 \%$; however, the additional $11 \%$ were exclusively performed laparoscopically and not without that assistance. ${ }^{[8]}$ Despite the introduction of $\mathrm{LH}, 66.1 \%$ of the hysterectomies performed in the USA are open abdominal hysterectomies..$^{[8]}$ The benefits of $\mathrm{VH}$ are similar to those of $\mathrm{LH}$, with minimal postoperative discomfort, less need for analgesics, shorter hospital stay and quicker return to normal daily activity compared with $\mathrm{AH}$. There are also fewer postoperative complications and reduced hospital costs in $\mathrm{VH}$ than $\mathrm{AH}$ and even $\mathrm{LH}^{\left[{ }^{[9-11]}\right.}$

\section{Objectives}

To explore the potential provider-related obstacles to offering less invasive hysterectomies, evaluate provider attitudes toward mode of access and inquire about provider-perceived contraindications to performing $\mathrm{VH}$ or $\mathrm{LH}$.

\section{Methods}

The study was based upon a two-page, anonymous, electronic survey that was designed to explore practising gynaecologists' preferences regarding the optimal hysterectomy procedure for benign uterine conditions and the perceived barriers towards MIH. The survey included questions on demographic characteristics, preferred approach to hysterectomy, the approximate number of surgical cases per year and potential barriers or contraindications for performing $\mathrm{VH}$ or $\mathrm{LH}$. A question enquiring whether surgeons have any intention of changing their approach to hysterectomy in the future was also included. 
The survey was created on Survey Monkey (Wufoo, USA). The questionnaire was designed to be brief and easy to read, so that practising gynaecologists need not spend an excessive amount of time completing it. The questionnaire was validated by 12 local practising gynaecologists who assessed the clarity and confirmed the relevance of the questions. Thereafter, the survey was amended to its present form. The study was approved by the Ethics Committee of the University of Witwatersrand (ref. no. M150462).

A link to the survey was emailed to all practising gynaecologists who are members of SASOG. A second email was sent out 2 weeks after the initial email to those who had failed to complete the questionnaire. To complete the survey, participants were asked to click on the link and thereby be directed to the survey. Since the completion of the survey was done online and the results were stored in bulk on the Survey Monkey server, anonymity was preserved. Moreover, no personal information was requested by the survey itself, so the identity of the participants was not revealed.

\section{Results}

A total of 152 responses were received from SASOG members, corresponding to a $29.5 \%$ response rate. The majority of the respondents were male (56.7\%). The average age of respondents was 45.7 years (Fig. 1), and $81.2 \%$ had $>5$ years' experience in private practice (Fig. 2). More than half (51.2\%) of the respondents practised in Gauteng Province, 27\% in the Western Cape and less than $10 \%$ elsewhere in South Africa (SA). The most commonly performed hysterectomy procedure that had been undertaken by the respondents in the last year was $\mathrm{TAH}$, followed by $\mathrm{VH}$ and TLH (Table 1). However, when asked about the preferred route of hysterectomy for themselves or their relatives, $25.5 \%$ chose TLH, $15.1 \%$ chose LAVH, $46.2 \%$ chose VH and $8.5 \%$ chose TAH (Fig. 3 ). Therefore, almost all of the respondents were more likely to choose a minimally invasive approach to hysterectomy, including $\mathrm{VH}$, for the patient benefits offered, as opposed to TAH (Fig. 4). Despite this, a preference for TAH in the daily practice of respondents was evident (Table 1).

The most significant reported barrier to performing $\mathrm{VH}$ was the lack of training during registrar time (31.0\%), followed by a lack of surgical experience (15.9\%), and then malpractice concerns and length of operating time (Table 2).

The most significant reported barriers to performing $\mathrm{LH}$ were lack of registrar training (29.3\%) and inadequate surgical experience (21.4\%), followed by hospital/patient cost, potential for complications and malpractice concerns (Table 3 ).

When asked about their ideal mode of access when performing hysterectomy, $23.8 \%$ of respondents answered TLH, $42.4 \% \mathrm{VH}$, $17.9 \%$ LAVH and $21.7 \%$ TAH (Table 4). The most significant contraindications for performing $\mathrm{VH}$ were adnexal mass, a history of endometriosis, lack of uterine descent, followed by previous pelvic inflammatory disease, narrow introitus, uterus larger than 12 weeks, and previous CS. When asked about their intention regarding changing the mode of access through which they perform hysterectomy, the majority of the respondents (66\%) indicated that they would like their TAH rates to remain the same. Only $29.1 \%$ of respondents stated that they would like to decrease their rates of TAH; 52.4 and $41.6 \%$ indicated that they intended to increase their $\mathrm{VH}$ and TLH rates, respectively, while keeping the same number of LAVHs (Table 5).

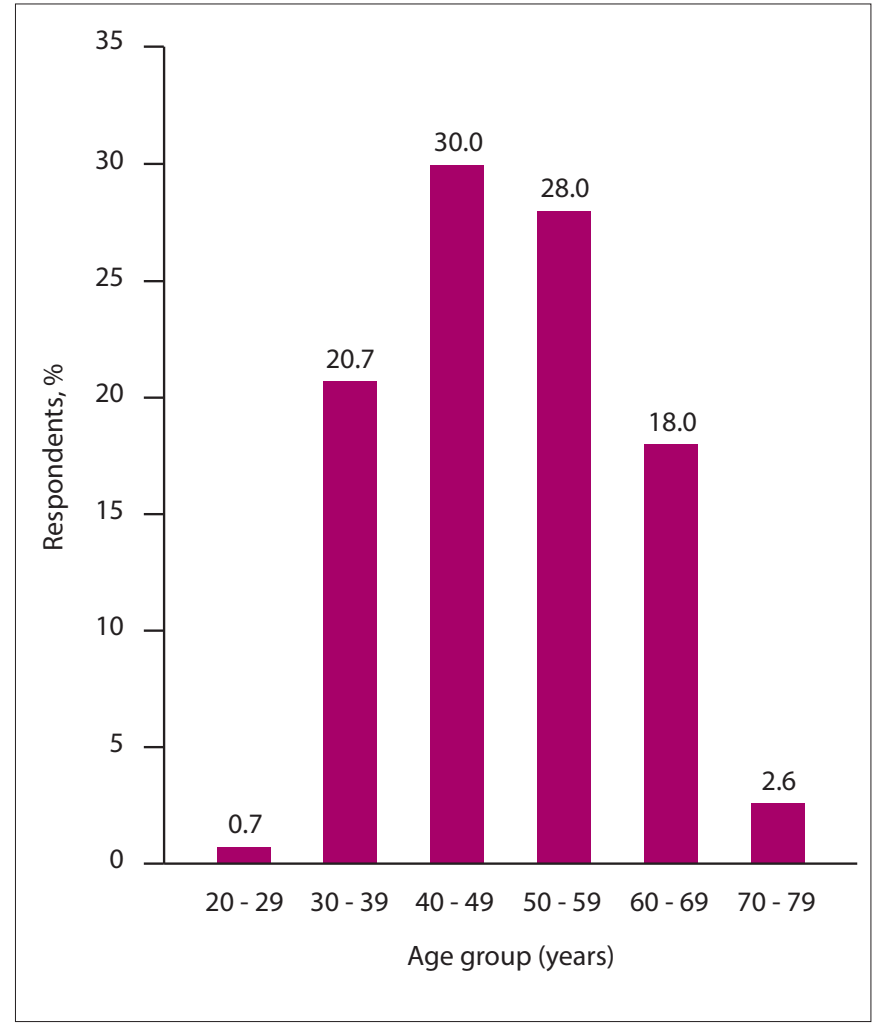

Fig. 1. Age distribution among respondents.

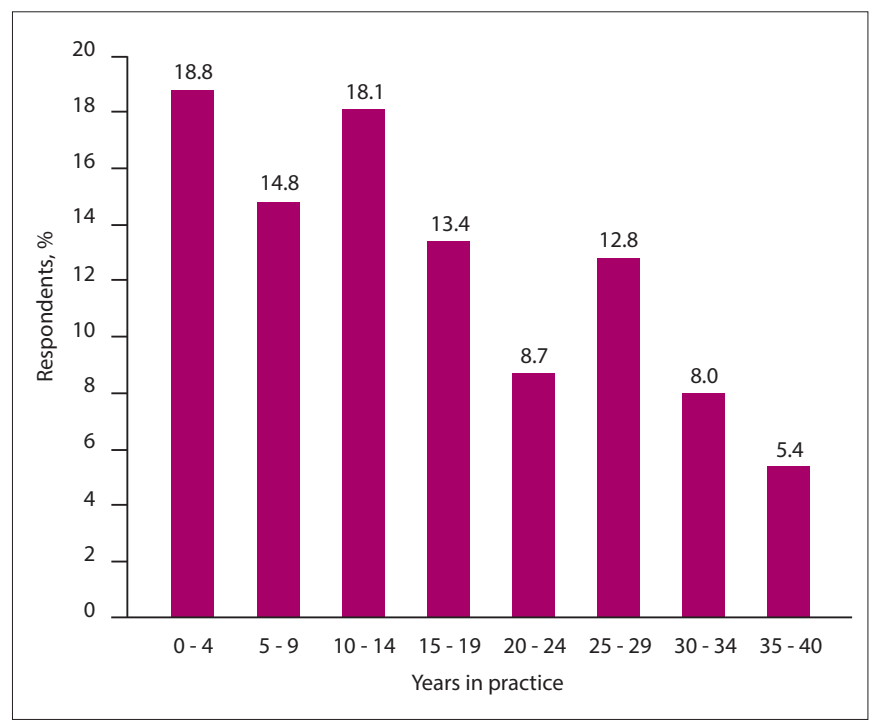

Fig. 2. Years in practice since completion of registration training.

\section{Discussion}

The majority of the respondents were between 30 and 69 years of age, with more than 5 years in practice since the completion of registrar training. All were members of SASOG. The survey was performed among practising gynaecologists with surgical experience in performing hysterectomy, with focus placed on their preferences between open and $\mathrm{MIH}$, including $\mathrm{VH}$. To the best of our knowledge, this was the first survey to evaluate barriers to performing less invasive hysterectomy in SA. The explicit aim of this study was to identify perceived barriers that deter practising gynaecologists from performing less invasive hysterectomy.

In our survey, we found discrepancies between practice patterns and physician preference. When practising gynaecologists were 


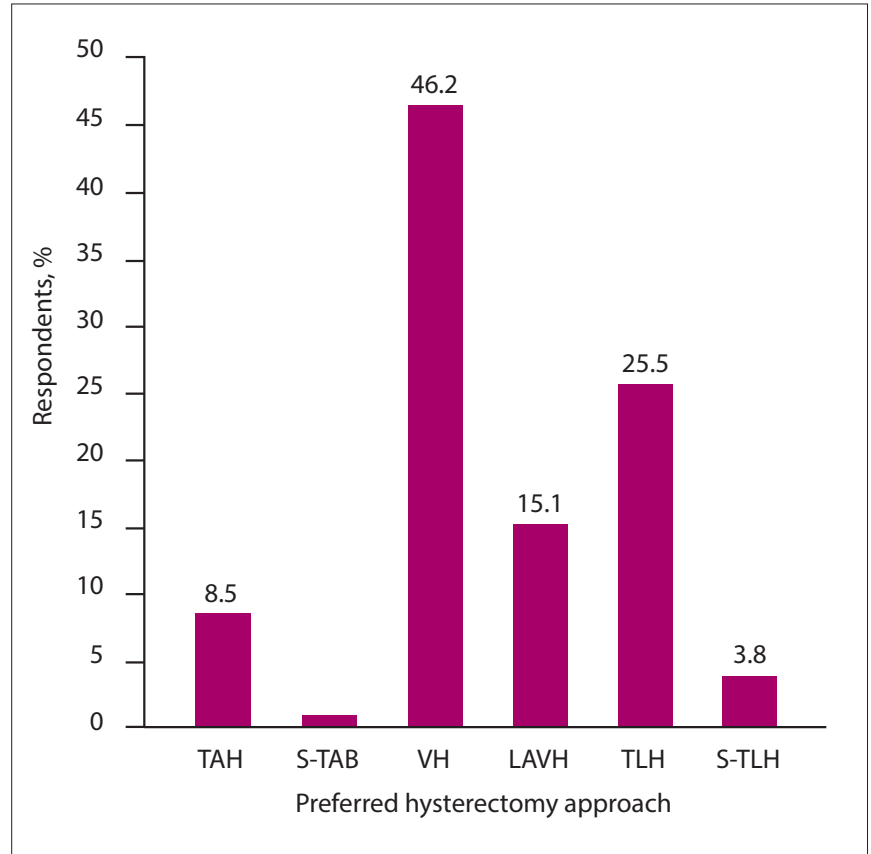

Fig. 3. Hysterectomy approach preferred for treatment of hypothetical non-malignant conditions to be applied to respondents or respondent's relatives. (TAH $=$ total abdominal hysterectomy; $\mathrm{S}-\mathrm{TAB}=$ subtotal abdominal hysterectomy; $\mathrm{VH}=$ vaginal hysterectomy; $L A V H=$ laparoscopically assisted vaginal hysterectomy; $T L H=$ total laparoscopic hysterectomy; S-TLH = subtotal laparoscopic hysterectomy.)

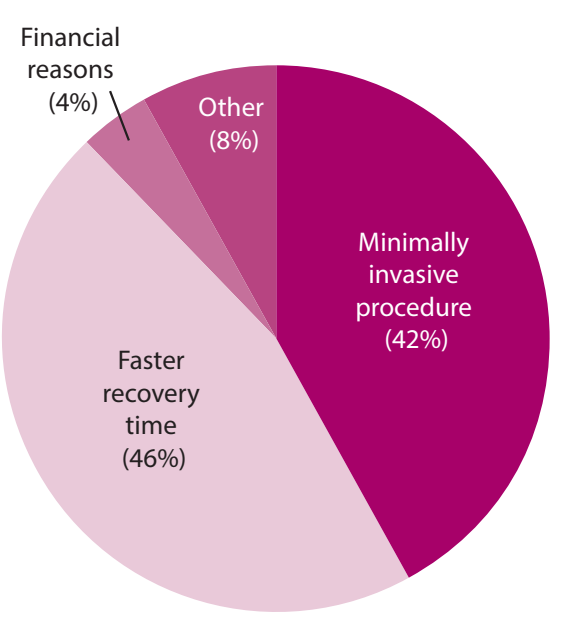

Fig. 4. The benefits of vaginal hysterectomy over total abdominal hysterectomy, as perceived by respondents. asked to rank which hysterectomy approach they would prefer for themselves or their relatives, $86.8 \%$ would prefer a $\mathrm{MIH}$, including TLH, LAVH and VH, compared with a TAH (8.5\%). When asked which route of hysterectomy they considered the most ideal, $42.4 \%$ of survey participants chose VH, followed by TLH, TAH and LAVH. However, the reality of their practice is different, as TAH still makes up a large majority of hysterectomies performed by respondents over the course of a 1-year period. Our results are in agreement with Einarsson et al. ${ }^{[12]}$ whose survey was performed in the USA among practising gynaecologists. While $8 \%$ of their respondents chose TAH as the preferred form of hysterectomy for themselves or their relatives, TAH remained the most commonly performed method. ${ }^{[12]}$ This difference between preference and practice could present an ethical dilemma for gynaecologists if they are not able to offer potentially appropriate candidates the hysterectomy they would recommend for themselves or their relatives. This demonstrates that in spite of the well-documented patient benefits of $\mathrm{MIH}$, including VH, LAVH and TLH, recognised by the respondents, the route of hysterectomy employed was still based on surgeon preference rather than patient benefits or condition. This seemed consistent with the findings of our study, as the participants expressed a desire to increase MIHs in their practice. They expressed a similar desire to increase their rates of $\mathrm{LH}$ (referring, in the context of this work, to both TLH and LAVH), as well as VH.

In the present study, the majority of the respondents indicated a reluctance to decrease the frequency of TAH and subtotal abdominal hysterectomy (S-TAB). These results are problematic in light of the fact that, although the majority of respondents recognised the benefits of $\mathrm{MIH}$ and, in particular, $\mathrm{VH}$, they remained unwilling to change their approach. We explored the perceived barriers to performing $\mathrm{VH}$ in order to understand the discrepancy between attitude and practice. Lack of surgical experience and training during registrar time, followed by malpractice concerns and length of operating time, were the main perceived barriers. When practising gynaecologists were asked to rank the contraindications to performing $\mathrm{VH}$, they prioritised adnexal mass, patients with endometriosis, patients with uterine fibroids, patients with previous CS, nulliparous patients, patients with previous laparotomies and lack of uterine descent.

Failure to achieve proficiency during training as a registrar was demonstrated in this survey as a severe obstacle to performing VH: lack of training and inadequate surgical experience featured in the majority of responses. Recent literature suggests that proficiency is achieved after 21 - 27 cases of $\mathrm{VH}$ are performed during residency. ${ }^{[1,1,14]}$ However, the current minimum requirement for $\mathrm{VH}$ in USA residency programmes is 15 cases, and in SA, only $5 \mathrm{VH}$ cases are required before sitting the final Fellow of the College of Obstetricians and Gynaecologists (FCOG) examination. This number of cases

Table 1. Frequency of various modes of hysterectomy access used by the respondents per year

\begin{tabular}{|c|c|c|c|c|c|c|c|}
\hline \multirow{2}{*}{$\begin{array}{l}\text { Hysterectomy } \\
\text { access }\end{array}$} & \multicolumn{6}{|c|}{ Number of procedures per year, $n(\%)$} & \multirow[b]{2}{*}{ Total } \\
\hline & $0-10$ & $10-20$ & $20-30$ & $30-40$ & $40-50$ & $50-60$ & \\
\hline TAH & $42.3(44)$ & $25.0(26)$ & $11.5(12)$ & $5.8(6)$ & $5.8(6)$ & $9.6(10)$ & 104 \\
\hline S-TAB & $94.4(84)$ & $3.37(3)$ & $2.3(2)$ & 0 & 0 & 0 & 89 \\
\hline VH & $60.0(60)$ & $20.0(20)$ & $8.0(8)$ & $6.0(6)$ & $3.0(3)$ & $3.0(3)$ & 100 \\
\hline LAVH & $91.9(60)$ & $5.8(5)$ & $2.3(2)$ & 0 & 0 & 0 & 86 \\
\hline TLH & $79.5(79)$ & $8.4(7)$ & $6.0(5)$ & $3.6(3)$ & 0 & $2.4(2)$ & 83 \\
\hline
\end{tabular}


RESEARCH

Table 2. The most significant barriers to performing $\mathrm{VH}$, as perceived by respondents

\begin{tabular}{|c|c|c|c|c|c|c|}
\hline \multirow[b]{2}{*}{ Obstacle } & \multicolumn{5}{|c|}{ Point scale, ${ }^{\star} n(\%)$} & \multirow[b]{2}{*}{ Total } \\
\hline & 1 & 2 & 3 & 4 & 5 & \\
\hline Registrar training time & $10(13.5)$ & $10(13.5)$ & $14(18.9)$ & $17(23.0)$ & $23(31.1)$ & 74 \\
\hline Operating time & $26(33.8)$ & $24(31.2)$ & $15(19.5)$ & $6(7.8)$ & $6(7.8)$ & 77 \\
\hline Surgical experience & $17(20.7)$ & $13(15.9)$ & $17(20.7)$ & $22(26.8)$ & $22(15.9)$ & 82 \\
\hline Malpractice concerns & $25(27.2)$ & $19(20.7)$ & $23(25.0)$ & $17(18.5)$ & $8(8.7)$ & 92 \\
\hline Other & $16(21.6)$ & $9(12.2)$ & $6(8.1)$ & $12(16.2)$ & $31(41.9)$ & 74 \\
\hline
\end{tabular}

*Scale $1-5$, where 1 represents the least significant barrier and 5 represents the most significant barrier.

Table 3. The most significant barriers to performing laparoscopic hysterectomy, as perceived by respondents

\begin{tabular}{|c|c|c|c|c|c|c|c|c|c|c|}
\hline \multirow[b]{2}{*}{ Obstacle } & \multicolumn{9}{|c|}{ Point scale, ${ }^{*} n(\%)$} & \multirow[b]{2}{*}{ Total $(n)$} \\
\hline & 1 & 2 & 3 & 4 & 5 & 6 & 7 & 8 & 9 & \\
\hline Registrar training time & $9(12.0)$ & $4(5.3)$ & $4(5.3)$ & $5(6.7)$ & $5(6.7)$ & $4(5.3)$ & $6(8.0)$ & $16(21.3)$ & $22(29.3)$ & 75 \\
\hline Operating time & $10(12.5)$ & $12(15.0)$ & $11(13.8)$ & $9(11.3)$ & $7(8.8)$ & $8(10.0)$ & $6(7.5)$ & $10(12.5)$ & $7(8.8)$ & 80 \\
\hline Surgical experience & $7(8.3)$ & $10(11.9)$ & $9(10.7)$ & $4(4.8)$ & $6(7.1)$ & $6(7.1)$ & $9(10.7)$ & $15(17.9)$ & $18(21.4)$ & 84 \\
\hline Technical difficulties & $2(2.4)$ & $2(2.4)$ & $13(15.7)$ & $15(18.1)$ & $12(14.5)$ & $15(18.1)$ & $14(16.9)$ & $7(8.4)$ & $3(3.6)$ & 83 \\
\hline Hospital/patient costs & $9(11.4)$ & $9(11.4)$ & $8(10.1)$ & $12(15.2)$ & $12(15.2)$ & $8(10.1)$ & $9(11.4)$ & $6(7.6)$ & $6(7.6)$ & 79 \\
\hline Potential complications & $1(1.3)$ & $7(8.8)$ & $6(7.5)$ & $15(18.8)$ & $21(26.3)$ & $12(15.0)$ & $10(12.5)$ & $4(5.0)$ & $4(5.0)$ & 80 \\
\hline Equipment availability & $9(10.1)$ & $10(11.2)$ & $16(18.0)$ & $7(7.9)$ & $13(14.6)$ & $12(13.5)$ & $13(14.6)$ & $2(2.3)$ & $7(7.9)$ & 89 \\
\hline Malpractice concerns & $4(4.7)$ & $18(20.9)$ & $6(7.0)$ & $7(8.1)$ & $8(9.3)$ & $10(11.6)$ & $13(15.1)$ & $13(15.1)$ & $7(8.1)$ & 86 \\
\hline Other & $19(31.7)$ & $3(5.0)$ & $5(8.3)$ & $1(1.7)$ & $1(1.7)$ & $2(3.3)$ & $2(3.3)$ & $9(15.0)$ & $18(30.0)$ & 60 \\
\hline
\end{tabular}

Table 4. Respondents' ideal mode of access when performing a hysterectomy

\begin{tabular}{|c|c|c|c|c|c|c|c|}
\hline \multirow[b]{2}{*}{ Hysterectomy access } & \multicolumn{6}{|c|}{ Point scale, ${ }^{\star} n(\%)$} & \multirow[b]{2}{*}{ Total $(n)$} \\
\hline & 1 & 2 & 3 & 4 & 5 & 6 & \\
\hline TAH & $20(21.7)$ & $16(17.4)$ & $23(25.0)$ & $9(9.8)$ & $12(13.0)$ & $12(13.0)$ & 92 \\
\hline S-TAB & $5(5.9)$ & $9(10.6)$ & $16(18.8)$ & $14(16.5)$ & $15(17.7)$ & $26(30.6)$ & 85 \\
\hline $\mathrm{VH}$ & $39(42.4)$ & $26(28.3)$ & $14(15.2)$ & $5(5.4)$ & $4(4.4)$ & $4(4.4)$ & 92 \\
\hline LAVH & $15(17.9)$ & $16(19.1)$ & $13(15.5)$ & $30(35.7)$ & $4(4.8)$ & $6(7.1)$ & 84 \\
\hline TLH & $20(23.8)$ & $10(11.9)$ & $14(16.7)$ & $8(9.5)$ & $17(20.2)$ & 15 (17.9) & 84 \\
\hline S-TLH & $3(3.5)$ & $7(8.1)$ & $6(7.0)$ & $12(14.0)$ & $30(34.9)$ & $28(32.6)$ & 86 \\
\hline
\end{tabular}

$\mathrm{TAH}=$ total abdominal hysterectomy; $\mathrm{S}-\mathrm{TAB}=$ subtotal abdominal hysterectomy; $\mathrm{VH}=$ vaginal hysterectomy; $\mathrm{LAVH}=$ laparoscopically assisted vaginal hysterectomy; TLH = total laparoscopic hysterectomy; S-TLH = subtotal laparoscopic hysterectomy. ${ }^{*}$ Scale $1-6$, where 1 represents the most ideal option and 6 represents the last choice.

Table 5. Respondents' intended changes regarding the mode of access exploitation when pursuing hysterectomy

\begin{tabular}{lllll}
\hline \multirow{2}{*}{$\begin{array}{l}\text { Hysterectomy } \\
\text { access }\end{array}$} & \multicolumn{4}{c}{ Change, $\boldsymbol{n}$ (\%) } \\
\cline { 2 - 5 } & To increase & To decrease & $\begin{array}{l}\text { To remain } \\
\text { unchanged }\end{array}$ & Total \\
\hline TAH & $5(4.9)$ & $30(29.1)$ & $68(66.0)$ & 103 \\
S-TAB & $4(4.1)$ & $33(34.4)$ & $59(61.5)$ & 96 \\
VH & $54(52.4)$ & $3(2.9)$ & $46(44.7)$ & 103 \\
LAVH & $40(42.5)$ & $9(9.6)$ & $45(47.9)$ & 94 \\
TLH & $40(41.6)$ & $9(9.4)$ & $47(49.0)$ & 96 \\
S-TLH & $13(14.0)$ & $22(23.7)$ & $58(62.3)$ & 93 \\
TAH = total abdominal hysterectomy; S-TAB = subtotal abdominal hysterectomy; \\
VH =vaginal hysterectomy; LAVH = laparoscopically assisted vaginal hysterectomy; \\
TLH = total laparoscopic hysterectomy; S-TLH = subtotal laparoscopic hysterectomy.
\end{tabular}

provides exposure, but definitely cannot ensure proficiency in performing VH. The American Association of Gynecologic Laparoscopists (AAGL), recognising the insufficient training during residency and the benefits offered by $\mathrm{VH}$ as compared with other minimally invasive techniques to hysterectomy, has stated that 'surgeons without the requisite training and skills required for the safe performance of $\mathrm{VH}$ or $\mathrm{LH}$ should enlist the aid of colleagues who do or should refer patients requiring hysterectomy to such individuals for their surgical care. ${ }^{\text {' }}{ }^{15]}$

The insufficient training in $\mathrm{VH}$ during residency results in a generation of gynaecologists unwilling to change their approach to hysterectomy. The reluctance among consultants to adapt to less invasive hysterectomy may have already affected the more recent generation of registrars, as one respondent in this study claimed that 'many consultants can't perform VH so can't train registrars in VH' Considering the contraindications to performing VH mentioned by the respondents, one can draw the conclusion that in the absence of uterine descent or prolapse, all hysterectomies are done either laparoscopically or abdominally in patients who may have otherwise undergone an uncomplicated $\mathrm{VH}$.

The contraindications to $\mathrm{VH}$ mentioned above should not be an obstacle to removing the uterus vaginally, provided the uterine size does not exceed 12 weeks, the pathology is confined to the uterus 
and there is adequate vaginal access. Many studies have shown that challenging these contraindications can lead to an increase in the numbers of $\mathrm{VH}$ performed. ${ }^{[4-6]}$ Recently, the International Society for Gynecologic Endoscopy (ISGE) released evidence-based guidelines, which include recommendations on the selection of women in whom $\mathrm{VH}$ can be safely performed. ${ }^{\left[{ }^{[16]}\right.}$

The most significant reported barriers to performing LH were chiefly a lack of surgical experience due to inadequate training, followed by the risk of complications resulting in malpractice concerns. The operating time was also a source of unease among respondents. Regarding $\mathrm{LH}$, the results of this survey were in agreement with those found among senior obstetrics and gynaecology residents by Einarsson et al. ${ }^{[17]}$ which showed that residents are unable to attain proficiency in most advanced laparoscopic procedures, including $\mathrm{LH}$, during their residency. In a survey performed in Canada, 93\% of respondents selected the endoscopic approach as their preferred approach, ${ }^{[18]}$ but, $38.7 \%$ of the respondents felt that they had not received adequate training during their residency to perform endoscopy in general.

A preference for minimally invasive techniques was also evident in the present study, where respondents considered $\mathrm{VH}$, followed by $\mathrm{LH}$, as the most ideal mode of access when performing hysterectomy. These results were in agreement with other large surveys among practising gynaecologists. ${ }^{[12,19,20]}$ As such, a global trend can be seen, demonstrated in both the literature and by our own study, in which the attitude towards minimally invasive techniques to hysterectomy is positive, but a lack of proficiency due to inadequate training during registrar time deters gynaecologists from acting on their preferences.

While lowered VH rates may well reflect a switch to laparoscopic procedures, ${ }^{[3,4,8]}$ our data indicate that the major cause of the decline in $\mathrm{VH}$ rates is a lack of training during registrar time, and experience.

Respondents favoured LAVH as their ideal mode of access when performing a hysterectomy, whereas the vaginal route was considered the most ideal for hysterectomy. This preference for LAVH was also observed in a survey conducted to assess modes of access in performed hysterectomies in Germany. ${ }^{[2]}$ These results may suggest that the laparoscopic technique was considered an aid to $\mathrm{VH}$ rather than a replacement for it. This is in agreement with a 2001 postal survey conducted in England among consultant gynaecologists that demonstrated that gynaecologists who performed many LHs had the highest $\mathrm{VH}$ rates, and predicted that $\mathrm{VH}$ would be further emphasised in years to come. ${ }^{[22]}$ It may be that LAVH could serve as the vehicle for performing more VHs in the future.

It must be stated that our study had limitations as well as strengths. The first of its strengths lay in the fact that our survey took place among general gynaecologists, in the style of the majority of surveys published in the literature..$^{[12,17-20]}$ Secondly, to the best of our knowledge, it is the first national survey conducted among SASOG members to evaluate barriers to performing MIH. However, our study was limited by its low response rate, as only $29.5 \%$ of potentially eligible doctors opted to complete the survey. This level of response is not unusual for electronic surveys, and in particular for surveys of doctors, ${ }^{[23]}$ for whom a lack of time and survey burden are well-documented impediments to participation. ${ }^{[2]}$ Furthermore, we acknowledge the potential for bias: it is possible that the respondents may not be representative of the overall population of minimally invasive gynaecological surgeons in practice in SA, which may have adversely affected our results.
Despite these possible limitations, we consider our hypothesis supported by the data collected through our survey. Insufficient training during registrar time and limited surgical experience were perceived as severe barriers when considering less invasive approaches to hysterectomy, thereby demonstrating that registrar training and experience indeed affect a surgeon's approach to hysterectomy. Furthermore, our data revealed that a positive attitude toward less invasive techniques does not necessarily reflect the surgeon's reality. $\mathrm{VH}$ and thereafter $\mathrm{LH}$ were considered ideal approaches to hysterectomy; however, TAH remained the surgeon's preferred practice. This, in conjunction with the sustained high number of TAH still performed worldwide, serves as a major indication that barriers to performing less invasive hysterectomies need to be addressed. Additional training opportunities to increase the numbers of $\mathrm{VH}$ and $\mathrm{LH}$ (namely TLH and LAVH) were suggested by the surgeons who answered the survey, and may be necessary to ensure that surgeons are capable of operating in accordance with their ideal method.

\section{Conclusion}

For the SASOG members who participated in our survey, preferences for the routes of hysterectomy compared with their actual practice appear inconsistent. The large discrepancy between practice and preference indicates that the route of surgery is more dependent on the clinical preference of the gynaecologist than the medical condition. Strategies should be initiated to increase training opportunities during registrar years in $\mathrm{MIH}$, especially $\mathrm{VH}$. Guidelines for performing MIH should be put in place to help our colleagues perform more $\mathrm{MIH}$, including $\mathrm{VH}$, in accordance with their ideal preferences.

\section{Declaration. None.}

Acknowledgements. None.

Author contributions. AC collected and processed the data, and wrote the article. DD analysed the data and edited the manuscript.

Funding. None.

Conflicts of interest. None.

1. Clayton RD. Hysterectomy. Best Pract Res Clin Obstet Gynaecol 2006;20(1):73-87. https://doi. org/10.1016/j.bpobgyn.2005.09.007

2. Johnson N, Barlow D, Lethaby A, Travender E, Curr E, Garry R. Surgical approach to hysterectomy for benign gynaecological disease. Cochrane Database Syst Rev 2006;(2):CD003677. https://doi. org/10.1002/14651858.CD003677.pub3

3. Vessey MP, Villard-Mackintosh L, McPherson K, Coulter A, Yeates D. The epidemiology of hysterectomy: Findings in a large cohort study. Br J Obstet Gynecol 1992;99(5):402-407. https://doi. org/10.1111/j.1471-0528.1992.tb13758.x

4. Raymond CD, Howard TS, Alder SC. Challenging generally accepted contraindications to vaginal hysterectomy. Am J Obstet Gynecol 2001;184:1386-1391. https://doi.org/10.1067/mob.2001.115047

5. McCracken G, Lefebvre GG. Vaginal hysterectomy: Dispelling the myths. J Obstet Gynecol Can 2007;29:424-428.

6. Kovac SR. Guidelines to determine the route of hysterectomy. Obstet Gynecol 1995;85(1):18-23. https://doi.org/10.1016/0029-7844(94)00318-8

7. Moen MD, Richter HE. Vaginal hysterectomy: Past, present, and future. Int Urogynecol J 2014;25(9):1161-1165. https://doi.org/10.1007/s00192-014-2459-x

8. Wu JM, Wechter ME, Geller EJ, Nguyen TV, Visco AG. Hysterectomy rates in the United States, 2003. Obstet Gynecol 2007;110(5):1091-1095. https://doi.org/10.1097/01.AOG.0000285997.38553.4b

9. David-Montefiore E, Rouzier R, Chapron C, Daraï E; Collegiale d'Obstétrique et Gynécologie de Paris-Ile de France. Surgical routes and complications of hysterectomy for benign disorders: A prospective observation study in French university hospitals. Hum Reprod 2007;22(1):260-265. https://doi.org/10.1093/humrep/del336

10. McPherson K, Metcalfe MA, Herbert A, et al. Severe complications of hysterectomy: The VALUE study. BJOG 2004;111(7):688-694. https://doi.org/10.1111/j.1471-0528.2004.00174.x

11. Kovac SR. Hysterectomy outcomes in patients with similar indications. Obstet Gynecol 2000;95(6 Pt 1):787-793. https://doi.org/10.1016/s0029-7844(99)00641-9

12. Einarsson JI, Matteson KA, Schulkin J, Chavan NR, Sangi-Haghpeykar H. Minimally invasive hysterectomies - a survey on attitudes and barriers among practicing gynaecologists. J Minim Invasive Gynecol 2010;17(2):167-175. https://doi.org/10.1016/j.jmig.2009.12.017 


\section{RESEARCH}

13. Toma A, Hopman WM, Gorwill RH. Hysterectomy at a Canadian tertiary care facility: Results of a oneyear retrospective review. BMC Women's Health 2004;4(1):10. https://doi.org/10.1186/1472-6874-4-10

14. Sheth SS. The scope of vaginal hysterectomy. Eur J Obstet Gynecol Reprod Biol 2004;115(2):224-230. https://doi.org/10.1016/j.ejogrb.2004.02.016

15. AAGL Advancing Minimally Invasive Gynecology Worldwide. AAGL position statement: Route of hysterectomy to treat benign uterine disease. J Minim Invasive Gynecol 2011;18(1):1-3. https://doj. org/10.1016/j.jmig.2010.10.001

16. Chrysostomou A, Djokovic D, Edridge W, van Herendael BJ. Evidence-based guidelines for vaginal hysterectomy of the International Society for Gynecologic Endoscopy (ISGE). Eur J Obstet Gynecol Reprod Biol 2018;231:262-267. https://doi.org/10.1016/j.ejogrb.2018.10.058

17. Einarsson JA, Young A, Tsien L, Sangi-Haghpeykar H. Perceived proficiency in endoscopic techniques among senior obstetrics and gynecology residents. J AM Assoc Gynecol Laparosc 2002;9(2):158-164. https://doi.org/10.1016/s1074-3804(05)60124-7

18. Chen I, Bajzak KI, Guo Y, Singh SS. A national survey of endoscopic practice among gynaecologists in Canada. J Obstet Gynaecol Can2012;34(2):257-263. https://doi.org/10.1016/s1701-2163(16)35186-6

19. Persson P, Helborg T, Brynhildsen J, Fredrikson M, Kjølhede P. Attitudes to mode of hysterectomy - a survey-based study amongst Swedish gynecologists. Acta Obstet Gynecol Scand 2009;88:267-274. https://doi.org/10.1080/00016340802649824
20. Janda M, Armfield NR, Kerr G, et al. Surgical approach to hysterectomy and barriers to using minimally invasive methods. Aust NZ J Obstet Gynaecol 2018;58(6):690-695. https://doi. org/10.1111/ajo.12824

21. David M, Wild D, Wernecke KD, Siedentopf F. Attitudes towards mode of hysterectomy: A surveybased study among German gynecologists. Eur J Obstet Gynecol Reprod Biol 2012;164(2):216-220 https://doi.org/10.1016/j.ejogrb.2012.06.023

22. Davies A, Magos A. The hysterectomy lottery. J Obstet Gynaecol 2001;21(2):166-170. https://doi. org/10.1080/01443610020026119

23. Nulty DD. The adequacy of response rates to online and paper surveys: What can be done? Assess Eval High Educ 2008;33(3):301-314. https://doi.org/10.1080/02602930701293231

24. Cunningham CT, Quan H, Hemmelgarn B, et al. Exploring physician specialist response rates to web-based surveys. BMC Med Res Methodol 2015;15(1):32. https://doi.org/10.1186/s12874015-0016-z

Accepted June 2020 